Article

\title{
Objectively-Assessed Physical Activity, Sedentary Behavior, Smartphone Use, and Sleep Patterns Pre- and during-COVID-19 Quarantine in Young Adults from Spain
}

\author{
Borja Sañudo ${ }^{1}\left(\mathbb{D}\right.$, Curtis Fennell ${ }^{2}$ and Antonio J. Sánchez-Oliver ${ }^{3, *(1)}$ \\ 1 Department of Physical Education and Sports, Faculty of Educational Sciences, Universidad de Sevilla, \\ 41013 Seville, Spain; bsancor@us.es \\ 2 Department of Exercise and Nutrition Science, University of Montevallo, Montevallo, AL 35115, USA; \\ cfennell@montevallo.edu \\ 3 Department of Human Motricity and Sports Performance, Universidad de Sevilla, 41013 Sevilla, Spain \\ * Correspondence: sanchezoliver@us.es; Tel.: +34-656305480
}

Received: 19 June 2020; Accepted: 20 July 2020; Published: 22 July 2020

check for updates

\begin{abstract}
This study assessed the effects of COVID-19 home confinement on physical activity, sedentary behavior, smartphone use, and sleep patterns. Data was collected in a sample of 20 young adults (mean age \pm SD: $22.6 \pm 3.4$ years; 55\% males) over seven days pre- and during the COVID-19 lockdown. Objective and subjective physical activity (Accelerometer and the International Physical Activity Questionnaire (IPAQ), respectively), the number of hours sitting (IPAQ), objectively-measured smartphone use (smartphone screen time applications), and objective and subjective sleep (accelerometer and the Pittsburgh Sleep Quality Index, respectively) were assessed. Results revealed significantly greater walking time and mean steps $(p<0.001, \mathrm{~d}=1.223$ to 1.605), and moderate and vigorous physical activity $(p<0.05, \mathrm{~d}=0.568$ to 0.616$)$, in the precompared with the during-COVID-19 lockdown phase. Additionally, smartphone use $(p=0.009$, $\mathrm{d}=0.654)$, sitting time $(p=0.002, \mathrm{~d}=1.120)$, and total sleep $(p<0.004, \mathrm{~d}=0.666)$ were significantly greater in the during- compared with the pre-COVID-19 lockdown phase. Multiple regressions analyses showed associations between physical activity and sedentary behavior and sleep quality. The number of hours sitting per day and moderate-to-vigorous physical activity significantly predicted deep sleep (adj. $R^{2}=0.46$ ). In conclusion, this study revealed that during the COVID-19 outbreak, behaviors changed, with participants spending less time engaging in physical activity, sitting more, spending more time using the smartphone, and sleeping more hours. These findings may be of importance to make recommendations, including lifestyle modifications during this time.
\end{abstract}

Keywords: home confinement; social isolation; COVID-19; lifestyle; physical health

\section{Introduction}

Social-distancing and home quarantine have been recommended by the World Health Organization (WHO) to minimize the speed of the coronavirus disease (COVID-19) spread. Spain is one of the most affected countries worldwide, despite the lockdown being imposed on 14 March 2020. Consequently, during this period, citizens have been forced to be isolated at home, prioritizing telecommuting and remaining at home except for "essential" tasks (e.g., purchasing groceries and medications, assisting those who are sick or disabled); therefore, outdoor physical activities have been suspended. Inevitably, this confinement is associated with a series of changes in our daily life activities, which usually lead to a sedentary behavior characterized by decreases in physical activity [1-3], increased sedentary (sitting) 
behavior [1], and an increase in the use of screen devices [4,5]. There is a major concern regarding the adverse effects of physical inactivity due to personal restrictions and how changes in the lifestyle would result in a range of chronic health conditions [6]. Consequently, research on the effects of the pandemic restrictions on physical activity can be considered a global public health need [7].

Recent evidence suggests there is an independent association between sedentary behavior and all-cause mortality, including cardiovascular disease [8]. In fact, increased sitting time (i.e., $>8 \mathrm{~h} /$ day) or screen time (3-4 h/day) are associated with increased risk of all-cause mortality, regardless of the levels of physical activity [9], and the deaths attributed to these unhealthy lifestyle behaviors are exponentially increasing in adults $[10,11]$. Because the COVID-19 lockdown prevents individuals from leaving their homes, including preventing access to outside sidewalks, parks, or fitness facilities, this could lead to decreased physical activity and increased sedentary behavior. The acute cessation of physical activity may incur metabolic and cardiovascular disturbances, promoting obesity and accelerating atherosclerotic disease [12]. For example, an abrupt decrease in the number of steps over a couple of weeks results in impaired insulin sensitivity and lipid metabolism [13]. Further, reduced physical activity levels and increased sedentary behaviors are known to affect the immune system and enhance the risk of severe infections in comparison to those who do regular physical activity $[7,14]$, and thereby can place an individual at greater risk of developing severe COVID-19 symptoms. Different organizations (e.g., WHO) have released guidelines for people in self-quarantine recommending sitting less and moving more while at home $[15,16]$. In addition to the detriments to physical health, lack of physical activity and large amounts of sedentary behavior are linked to psychological well-being, such as decreased mental health, including depression $[17,18]$. Moreover, other lifestyle habits (i.e., sleep) are able to modulate immune functions and improve the adaptive immune response against the antigen, even during COVID-19 outbreak [19]. Furthermore, the evidence is wide suggesting the positive association between sleep and mental health [20-22].

Changes in social life and the daily routine (i.e., loneliness, lower exposure to the sun, as well as increased use of electronic devices) together with the imposed stress on individuals (i.e., insecurity about their health or financial consequences), has also been reported to negatively affect sleep patterns [19,23-25], leading to high rates of sleeplessness [26]. Low activity levels (during the day also) affect sleep negatively [24]. Moreover, people spend more time using screens during the quarantine, and in young adults this was also associated with a growing prevalence of sleep problems [27]. The use of screens can ameliorate social isolation; however, these behaviors (e.g., smartphone use) can have a negative influence on the levels of physical activity, sedentary behavior, and sleep patterns [28]. Likewise, different coping strategies have been recommended by the WHO to address the psychological effects of the COVID-19 outbreak, including rest, physical activities, and staying in contact with family and friends. Moreover, reductions in media viewing $90 \mathrm{~min}$ before bedtime have also been advised [26].

Despite the attempts to prevent the changes in physical activity [1,2,25], sedentary behavior (e.g., sitting or media use) $[25,29]$, and sleep $[24,25,29,30]$ forced by the lockdown, the evidence is limited regarding the effect of confinement on physical activity, sedentary behavior, smartphone use, and sleep patterns. Further, all of the previous studies on this topic have used subjective tools; therefore, objective and quantitative ways to monitor population behavior are required in order to determine the impact of the measures adopted by the government and suggest strategies for possible confinements in the near future [4]. By means of built-in sensors in smartphones and wearable technologies, the remote monitoring of human behavior is possible [31] and consequently, lifestyle modifications during this time could be recommended. The present paper presents preliminary data on physical activity, sedentary behavior, smartphone use, and sleep patterns before and during home confinement during the COVID-19 lockdown, collected from wearable devices (including step counts and sleep patterns) and by smartphones (smartphone usage), which may be altered by changes in lifestyle due to social isolation [4]. Specifically, we aimed at determining to what extent physical activity, sedentary behavior, smartphone use, and sleep patterns changed during the COVID-19 lockdown, and to investigate which lifestyle factors should be considered as moderators of these changes. Our hypothesis was that 
COVID-19 lockdown will result in less physical activity, greater sedentary behavior, greater smartphone use, and high sleep amount and quality than pre-COVID-19 lockdown.

\section{Materials and Methods}

\subsection{Sample}

Participants were recruited by flyers and by researchers speaking to classes and class e-mails. A total of 139 students were initially identified, but 78 refused to participate, and 4 students were excluded for health problems $(n=3)$ or medication (i.e., treatment of insomnia) that could induce changes in the study variables. Consequently, in the pre-lockdown phase, the sample consisted of 57 college students aged $20-36$ years (mean age \pm SD: $22.5 \pm 2.6$ years; $61 \%$ males) who were selected from different schools in the city of Seville. This population group was selected because young adults are likely to use the smartphone, and they are especially at risk of sleep disturbance [32]. Participants were excluded if they had any health problem that temporarily or permanently prevented participation in physical activity (e.g., musculoskeletal disorder, nervous system disease, etc.) or used any type of medication that could induce changes in the study variables (e.g., opioids or antidepressants). In the during-lockdown phase, all participants who still had the wristband accelerometer provided by the researchers in the pre-lockdown phase $(n=40)$, were contacted again by e-mail for the during-lockdown phase, but 16 refused to participate and 2 students experienced problems with the software. Finally, 22 college students aged $20-36$ years (mean age \pm SD: $22.7 \pm 3.6$ years; $57 \%$ males) that completed the pre-lockdown phase were included. The study was conducted according to the Declaration of Helsinki, and all participants signed informed consent. The study protocol was approved by an ethical committee (0319-N-19).

\subsection{Data Collection and Procedures}

Data already collected for a one-week period from February 2020 onwards as part of a dissertation were used as the pre-lockdown phase data time point. Once the lockdown was imposed in Spain on 14 March 2020, the participants were again assessed for a one-week period of time from 24 March to 3 April 2020. Data were automatically uploaded to a computer data base through a smartphone (phone usage data) and a wrist band (steps and sleep). In the first phase, researchers explained the study protocol and objectives to the participants, which are fully described elsewhere [28]. Briefly, participants filled out questionnaires on subjective physical activity and subjective sedentary behavior, and were shown how to submit the report after one week. To objectively measure smartphone use, Android smartphone users were instructed to download the application "Your Hour", which is a phone addiction tracker and controller (Mind-e-fy Solutions, Madhya Pradesh, India), and iPhone smartphone users were instructed to use the "Screen Time" application (a built-in application on the iPhone) for iOS. The number of steps and the sleep patterns were automatically registered using the wristband accelerometer (Xiaomi Mi Band 2, Beijing, China). This wristband was reported to be valid and reliable for measuring heart rate, number of steps, distance, and sleep duration, which can be used as effective health evaluation indicators [33]. Participants were instructed to wear the accelerometer for 7 consecutive days and to remove it only when bathing or showering.

In the during-lockdown phase, the mobility (i.e., driving, walking, etc.) was reduced due to the restrictions; in the during-lockdown phase, due to the restrictions, mobility (i.e., driving, walking, etc.) was restricted; therefore, only those who had the necessary equipment (e.g., accelerometer, etc.) could be contacted. Researchers contacted the participants again and verified that the smartphone and wristband were working correctly, helping each one to complete the questionnaires again. Data was collected for a one-week period of time. 


\subsection{Measurements}

Data on sex and age, sociodemographic information including education (degree and course), and occupational data (type of employment) were collected. Objective and subjective physical activity (i.e., frequency and intensity) and subjective sedentary behaviors (i.e., sitting time) were assessed [34]. The number of steps and the sleep patterns were objectively measured. Quality of sleep and sleep time were also objectively and subjectively assessed. Finally, smartphone use was objectively measured.

\subsection{Physical Activity and Sedentary Behavior}

Physical activity and sedentary behavior were subjectively measured with the Spanish version of the International Physical Activity Questionnaire (IPAQ), which is a validated questionnaire that measures the participation in vigorous- and moderate-intensity physical activity and sedentary behavior over the past seven days [34]. Outcome measures from the IPAQ were (a) total physical activity expressed as minutes per day and minutes reported in (b) vigorous-intensity, (c) moderate-intensity activity, (d) walking time, and (e) in sitting per day. Moderate-to-vigorous intensity activity was then calculated by summing vigorous- and moderate-intensity physical activity. As indicated above, to objectively measure the number of steps, participants use the Xiaomi Mi Band 2 wrist-worn accelerometer (Beijing, China).

\subsection{Smartphone Usage}

Objective smartphone use, including the smartphone screen-state (time during which the smartphone is unlocked, and the screen is on) accumulated by participants over seven consecutive days was objectively captured. Average screen-state time (in minutes) per weekdays and weekends for all users was used as the outcome measure.

\subsection{Sleep Quality and Quantity}

The Xiaomi Mi Band 2 was also used to quantify sleep structure. This device continuously assesses body movement by accelerometry, a proximity sensor, and a photoplethysmography sensor to monitor blood-volume changes [35]. These data are Bluetooth-transferred to the smartphone accessible through Mi Fit software (algorithm v1.1.14, Anhui Humai Information Technology CO., Ltd., Hefei, China). The device classifies sleep into deep and light sleep based on body movements. Total Sleep Time and Awake Time were also recorded.

Perceived sleep quality in the past month was assessed using the Spanish version of the Pittsburgh Sleep Quality Index (PSQI) [36]. This self-report questionnaire consists of 19 items weighted on a 0-3 interval scale and grouped in seven component scores (subjective sleep quality, sleep latency, sleep duration, use of sleeping medication, daytime dysfunction, and habitual sleep efficiency). The outcome measure was the global PSQI score (range, 0-21). Scores higher than 5 indicate poor sleep.

\subsection{Statistical Analysis}

Data were reported as means (standard deviations) for continuous variables or percentages for categorical variables. To examine physical activity, sedentary behavior, smartphone use, and sleep differences induced by the lockdown, comparisons among pre-, and during-lockdown were carried out using Wilcoxon signed-rank tests. Effect size (Cohen's d) was calculated to determine the magnitude of the change of the score and was interpreted using the following criteria: 0.2 (small), 0.5 (moderate), and 0.8 (large). To investigate the associations between physical activity during the lockdown and changes in sedentary behaviors, smartphone use, and sleep, multiple linear regressions were conducted accounting for other covariates (e.g., sex, weight, and age). A $p$-value $<0.05$ was deemed statistically significant. Poor sleep quality is defined as PSQI global score $>5$ [37]. Smartphone screen time was categorized as $<2$ and $\geq 2 \mathrm{~h}$ per day [38]. Statistical analyses were performed using Jamovi 1.1.9 software for mac (Jamovi Project. Available from: https://www.jamovi.org). 


\section{Results}

The final study sample was composed of 54 ( $\mathrm{n}=2$ experienced problems with the wristband, and $n=1$ decided not to participate) young adults in the pre-lockdown phase. Only $20(n=2$ experienced problems with the wristband) completed all seven days of data recorded both in the pre and the during-lockdown phase (mean age \pm SD: $22.6 \pm 3.4$ years; $55 \%$ males). Therefore, all the analyses were performed with this sample of 20 participants (characteristics of the participants can be found in Table 1). While all participants were students, in the pre-lockdown phase, $60 \%$ of the sample were also working, and in the during-lockdown phase, five of them lost their jobs ( $35 \%$ were workers).

Table 1. Characteristics of the participants in the study $(n=20)$.

\begin{tabular}{|c|c|c|c|c|}
\hline Variables & Pre-Lockdown & During-Lockdown & $p$-Value & Cohen's d \\
\hline Age, mean (SD) & & $22.6(3.4)$ & & \\
\hline Gender (\%female) & & 47 & & \\
\hline \multicolumn{5}{|l|}{ Professional status, n (\%) } \\
\hline Work full/part time & $12(60)$ & $7(35)$ & & \\
\hline Unemployed & $8(40)$ & $13(65)$ & & \\
\hline \multicolumn{5}{|l|}{ Subjectively measured physical activity } \\
\hline Walking time (min/week) & $362(262)$ & $27(47)$ & $<0.001$ & 1.223 \\
\hline Moderate PA (min/week) & $441(487)$ & $178(155)$ & 0.028 & 0.727 \\
\hline Vigorous PA (min/week) & $356(381)$ & $168(228)$ & 0.006 & -0.568 \\
\hline Moderate-to-vigorous PA (min/week) & $797(822)$ & $346(341)$ & 0.005 & 0.616 \\
\hline \multicolumn{5}{|l|}{ Objectively measured physical activity } \\
\hline Mean steps (steps/day) & $8525(3597)$ & $2754(1724)$ & $<0.001$ & 1.605 \\
\hline \multicolumn{5}{|l|}{ Subjectively measured Sedentary behavior } \\
\hline Sitting time (hours/day) & $6.4(2.6)$ & $9.7(2.9)$ & 0.002 & -1.120 \\
\hline Meeting WHO PA guidelines, yes (\%) ${ }^{c}$ & 84 & 74 & 0.530 & -0.160 \\
\hline \multicolumn{5}{|c|}{ Objectively measured Sleep quality and quantity } \\
\hline Total sleep (min/day) & $473(57.3)$ & $507(66.6)$ & 0.004 & -0.666 \\
\hline Deep sleep (min/day) & $134(36.8)$ & $145(40.6)$ & 0.107 & -0.330 \\
\hline Weak sleep (min/day) & $337(63.0)$ & $357(67.6)$ & 0.096 & -0.481 \\
\hline PSQI Global Score $(0-21)^{b}$ & $5.8(2.7)$ & $6.8(3.8)$ & 0.366 & -0.273 \\
\hline Impaired sleep (PSQI score > 5), (\%) & 47 & 58 & 0.484 & 0.186 \\
\hline \multicolumn{5}{|l|}{ Objectively measured Smartphone use } \\
\hline Mean usage (min/day) & $370(166)$ & $491(240)$ & 0.009 & -0.654 \\
\hline
\end{tabular}

PA, Physical activity; ${ }^{b}$ PSQI, Pittsburgh Sleep Quality Index. Higher scores reflect greater sleep disturbance. ${ }^{c}$ Meeting WHO (World Health Organization) PA guidelines: Accumulating $150 \mathrm{~min} /$ week of moderate physical activity or $75 \mathrm{~min} /$ week of vigorous physical activity or equivalent combination of moderate and vigorous physical activity.

\subsection{Physical Activity and Sedentary Behavior Pre-and during the Confinement Period}

Of the participants, $84 \%$ met the WHO physical activity guidelines of accumulating $150 \mathrm{~min} /$ week of moderate physical activity, $75 \mathrm{~min} /$ week of vigorous physical activity, or equivalent combination of moderate- and vigorous-intensity physical activity in the pre-lockdown phase and $74 \%$ met the guidelines in the during-lockdown phase. Physical activity changes recorded before and during the lockdown are presented in Table 1. The number of subjectively-measured min/day of walking time, moderate-intensity, and vigorous-intensity physical activity before and during the home confinement significantly decreased by $92 \%(p<0.001, \mathrm{~d}=1.223)$, by $78 \%(p=0.028, \mathrm{~d}=0.616)$, and by $53 \%$ ( $p=0.006, \mathrm{~d}=-0.568)$, respectively. Likewise, the number of steps/day (objectively measured physical activity) significantly decreased by $68 \%$ during home confinement $(p<0.001, d=1.605)$. The subjectively-measured hours/day of sitting time significantly increased by $52 \%$ during home confinement $(p=0.002, \mathrm{~d}=-1.120)$. 


\subsection{Smartphone Use Pre- and during the Confinement Period}

There was a significant increase in objectively-measured smartphone use during the confinement $(p=0.009, \mathrm{~d}=-0.654)$ compared with pre-confinement.

\subsection{Sleep Quality and Quantity Pre- and during the Confinement Period}

Of the participants, 47 and 58\% were classified as poor sleepers (PSQI score $>5$ ) in the pre- and the during-lockdown phase, respectively. Regarding the changes in sleep habits objectively measured with the wristband accelerometer, significant differences were observed in the total sleep ( $\mathrm{min} /$ day), which increased by $7 \%(p=0.004, d=-0.666)$ from pre- to during-quarantine. Subjectively measured quality of sleep showed a non-significant increase of the PSQI score under the restriction $(p=0.366$, $\mathrm{d}=-0.273$ ) from pre- to during-quarantine. Participants delayed their wake time by $\sim 12 \mathrm{~min}$, whereas they fell asleep $\sim 120$ min earlier.

Table 2 shows the results of different multiple regressions analyses testing the associations between physical activity, sedentary behavior (sitting time), the time using the smartphone, and sleep. The number of steps (standardized coefficients, $\beta=0.574 ; 95 \% \mathrm{CI}=0.19,0.95 ; p<0.01$ ) significantly positively predicted higher quality of sleep, the min/week of vigorous physical activity (standardized coefficients, $\beta=0.421 ; 95 \% \mathrm{CI}=-0.03,0.32 ; p<0.05$ ) significantly positively predicted higher quality of sleep, and moderate-to-vigorous physical activity (standardized coefficients, $\beta=0.438 ; 95 \% \mathrm{CI}=-0.01$, $0.88 ; p<0.05)$ significantly positively predicted higher quality of sleep. The min/week of vigorous physical activity significantly negatively predicted total sleep (standardized coefficients, $\beta=-0.530 ; 95 \%$ $C I=-1.01,-0.05 ; p<0.05$ ) and deep sleep (standardized coefficients, $\beta=-0.412 ; 95 \% C I=-0.83,0.01$; $p<0.05$ ). Additionally, the number of hours sitting per day (standardized coefficients, $\beta=-0.326$; $95 \%$ $\mathrm{CI}=-0.70,0.05 ; p>0.05$ ) and the $\mathrm{min} /$ week of moderate-to-vigorous physical activity (standardized coefficients, $\beta=-0.420 ; 95 \% \mathrm{CI}=-0.81,-0.03 ; p<0.05$ ) significantly negatively predicted deep sleep. The model explained $46 \%$ of the variance in the deep sleep $\left(\mathrm{F}_{1,20}=4.91, p=0.011\right.$, Adj. $\left.R^{2}=0.465\right)$.

Table 2. Individual associations of physical activity, hour sitting, and smartphone use with sleep variables.

\begin{tabular}{|c|c|c|c|c|c|c|}
\hline \multirow[b]{2}{*}{ Outcome } & \multirow[b]{2}{*}{ Predictor } & \multirow[b]{2}{*}{ B } & \multirow[b]{2}{*}{ Adjusted $\mathbf{R}^{2}$} & \multirow[b]{2}{*}{$\beta$} & \multicolumn{2}{|c|}{ 95\% Confidence Interval } \\
\hline & & & & & Lower & Upper \\
\hline \multirow{5}{*}{ PSQI Global Score } & Pos_Mean steps & $0.001^{* *}$ & 0.47 & 0.574 & 0.194 & 0.955 \\
\hline & Pos_VPA & $0.007^{*}$ & 0.29 & 0.421 & -0.027 & 0.870 \\
\hline & Pos_MVPA & $0.005^{*}$ & 0.31 & 0.438 & -0.001 & 0.883 \\
\hline & Pos_Mean steps & $0.001^{*}$ & \multirow{2}{*}{0.50} & 0.482 & 0.080 & 0.884 \\
\hline & Pos_MVPA & 0.003 & & 0.255 & -0.157 & 0.666 \\
\hline \multirow{2}{*}{ Total sleep } & Pos_VPA & $-0.155^{*}$ & 0.19 & -0.530 & -1.011 & -0.050 \\
\hline & Pos_MVPA & $-0.093^{*}$ & 0.13 & -0.475 & -0.975 & 0.025 \\
\hline \multirow{3}{*}{ Deep sleep } & Pos_VPA & $-0.073^{*}$ & 0.38 & -0.412 & -0.833 & 0.010 \\
\hline & Pos_Sitting time & 0.076 & \multirow{2}{*}{0.46} & -0.326 & -0.699 & 0.046 \\
\hline & Pos_MVPA & $-0.050^{*}$ & & -0.420 & -0.814 & -0.026 \\
\hline
\end{tabular}

B, non-standardized coefficient; $\beta$ standardized coefficient; CI, confidence interval; Model, $\beta$ (95\%CI): Adjusted for age and gender; PSQI, Pittsburgh Sleep Quality Index. VPA, Vigorous Physical activity; MVPA, Moderate to Vigorous Physical activity. Significant associations are highlighted with asterisks ${ }^{*} p \leq 0.05,{ }^{* *} p \leq 0.01$.

\section{Discussion}

This study assessed the effects of home quarantine during the COVID-19 pandemic on physical activity, sedentary behavior, smartphone use, and sleep patterns, by collecting objective smartphone use and objective physical activity data. As expected, lifestyle changed during the quarantine in the 
participants, as they exhibited less engagement in physical activity, and more time spent sitting, using smartphones, and sleeping.

The results herein demonstrate that individual's routines may have changed due to the COVID-19 lockdown. Participants spent more time at home and consequently, the number of objectively-measured steps were significantly reduced. Many opportunities to be physically active have been suspended in Spain, and despite people following online exercise classes [16], the time expended in moderate-intensity or vigorous-intensity physical activity during the home confinement decreased by $92 \%$ compared to pre-confinement. This is consistent with recent publications showing a decline in all physical activity levels during the home confinement $[1,2,25]$. In France and Switzerland, there was shown to be a decline of $15 \mathrm{~min} /$ day of physical activity [2], while in Italy and Spain [25], people also spent less time daily performing physical activity, with only $15 \%$ of the individuals achieving at least $60 \mathrm{~min}$ of physical activity during the quarantine. This can be attributed to the differences in the measures adopted by the different governments during the quarantine (e.g., some governments allowed physical activity practice while others did not). Culture of practice of physical activity in the different countries, type of population measured or possibility of space at home to do it, among others [39]. In the current study, physical activity at different intensities was significantly reduced $(\mathrm{d}=0.568$ to 1.223$)$, while the objectively measured number of steps/days decreased by $68 \%$ during home confinement $(p<0.001$, $\mathrm{d}=1.605$ ). As reported in the introduction section, these reduced amounts of physical activity levels may lead to developing metabolic and cardiovascular disease [12]. To counteract these undesirable effects, recent evidence suggests taking as little as 4000 steps per day to improve long-term health [11].

Numerous studies have recently highlighted the importance of continuing to move during confinement; however, considering that people were required to stay at home in the quarantine, the sedentary behavior levels increased. One of the most prominent changes in the current study was observed in sitting behavior, which increased an average of 3.3 hours/day during quarantine. The effect size was similar to a recent study performed in a sample of US adults [1] that compared pre- to during-confinement, to demonstrate the proportion of individuals who sat for 6-8 hours/day increased from $24 \%$ to $29 \%$ and those who sat for more than 8 hours/day increased from $16 \%$ to $40 \%$ from pre- to during-confinement. This is consistent with the results reported in another study in a sample of young adults from France and Switzerland [2] that also showed more time ( $76 \mathrm{~min} /$ day) was spent on sedentary behaviors during home confinement compared with pre-confinement [2]. Inevitably, these behaviors have a harmful effect on health $[8,40]$; therefore, it is important to establish policies to maintain the $4-5$ hours/day limits to sedentary behavior established in the literature [41].

In Spain, previous research has shown sedentary behavior to be associated with objectively assessed smartphone use patterns [28]. Likewise, these sedentary behaviors were associated with increasing COVID-19 related news [5]. During the quarantine, people spent more time on sedentary behaviors, and this was likely to increase the use of these devices. We showed an increase of $\sim 2$ hours/day using the smartphone during the lockdown, which is consistent with recent reports showing that adults spend more time daily using screens (i.e., smartphones or computers) [42]. In Denmark, the use of these devices increased by $185 \%$ with the lockdown announcement [4], and this increased activity with the smartphone also occurred in other countries, such as Italy, Spain, the UK, or the Netherlands [4]. It is interesting to note that the increase in digital media use before going to bed affected sleep latency and wake time; however, does not affect sleep quality [29].

Staying at home without the chance to go outside have been suggested to increase sleep problems [25]. In any case, sleep habits have also changed during the quarantine [24], which may have important implications to improve immunity to viral infection [43]. In the current study, increments in total sleep ( $\sim 5 \mathrm{~min} /$ day $)$ were observed, with participants delaying their wake time by $\sim 12 \mathrm{~min}$, but a significant change in sleep quality was not observed. This is in agreement with previous studies showing that students delayed their wake time by $\sim 45 \mathrm{~min}$ and spent $\sim 5 \mathrm{~min}$ more in bed than before the restrictions, without changes in sleep quality [29], which is consistent with other studies [4]. One possible explanation for these discrepancies can be attributable to the interactions between 
behaviors and the differences in policies for the lockdown. In our study, we observed that the time spent active (number of steps or moderate intensity activities) was significantly associated with sleep quality and both sedentary behavior (i.e., sitting time) and physical activity (moderate-to-vigorous physical activity) were significant predictors of deep sleep. Previous studies suggest the activity levels during the day, such as low levels of activity (due to the confinement) may affect sleep negatively [24]. Although physical activity levels decreased during quarantine, sleep increased. However, consistent with previous studies, the current investigation demonstrated an association between higher levels of physical activity and improvements in sleep quality [44]. Therefore, it seems that sleep time during quarantine was improved, but this many not have been due to the physical activity performed; rather, it was potentially due to having more time to sleep and not needing to wake up early for activities (e.g., school, work, etc.).

Some limitations must be acknowledged. First, the study was conducted on a small sample size of college students, which may have limited the comparison between some variables or the establishment of certain subgroups. Despite this, the sample was homogeneous, and the evaluation instruments were objective. Further, this was the first study done in Spain on these variables during COVID-19 quarantine. In any case, and while strong significant effects on behavior were observed, the study findings should be interpreted with caution, limiting the generalizability of the results to the general population, including adults who have children. Second, as recommended, both objective and subjective measures (self-report questionnaires) were used to increase the accuracy and capture context-specific physical activity behaviors [7]; however, the measure of physical activity (IPAQ), sedentary behavior (IPAQ), and sleep quality (PSQI) were self-reported and retrospective, which may involve recall bias. Moreover, sometimes when people are at home they do not have their smartphones with them at all times, which could affect sedentary analyzes [5]. To solve this, we contrast these measures with those obtained with the wristband (objectively-measured), thus limiting possible errors. Lastly, and despite the longitudinal design that allows us to assess the associations between changes in physical activity, sedentary behaviors, smartphone use, and changes in sleep outcomes during the lockdown, there could be differences in these variables throughout the confinement; therefore, because our study was performed over one week of the lockdown, this may not have allowed time for significant changes in any of the variables.

\section{Conclusions and Future Directions}

Objective and subjective data from smartphones and wearable devices were obtained before and during the COVID-19 outbreak. This study revealed that, as expected, when comparing pre-COVID-19 to during the COVID-19 outbreak, participant's behaviors changed by engaging in less physical activity, sitting more, spending more time using smartphones, and sleeping more hours. These findings may be of importance to make preliminary recommendations concerning necessary self-care focusing on staying active (maintaining and improving physical activity levels), reducing sitting, and moderating smartphone use, since it has been shown that these variables improve mental (e.g., well-being, sleep) and physical health [6].

There is a global concern to collect these data in order to support decision making and to provide timely interventions, including lifestyle modifications during this time [45]. The devices used in the current study to assess the changes in behavior might be particularly important in understanding the consequences of the quarantine and to monitor the effects of social distancing measures in future pandemics or even understand behavior patterns once life begins to return to normal. As discussed here, the undesirable effects of the measures taken in this pandemic (i.e., confinement, social distancing) could have a negative impact on future pandemics [46]. Consequently, future studies are needed to develop public health promotion in order to maintain a healthy lifestyle before as well as during isolation.

One of the effects of the current quarantine generated by COVID-19 is the limitation of spaces and the restriction to do outdoor activities [39]. This directly affects the physical activity that people do, since there is a need for physical activity in their daily routine (walking, climbing stairs, etc.). This lack 
of informal and unplanned physical activity during confinement can be counteracted by performing scheduled physical activity through vigorous or medium intensity exercise [47]. Home exercise programs are considered effective, safe, and low cost when performed under guidance, according to the specificities of each individual, promoting gains in physical fitness and health-related skills, and positively impacting overall quality of life [48]. Such programs present a promising and effective alternative to increase and maintain the levels of physical activity in the population and the immune response to COVID-19, which should be adopted as a public health policy [47]. Additionally, there is a need to introduce specific guidelines for sedentary behavior [49]. Therefore, the authors of this study recommend public health messages be delivered to encourage movement of any intensity, reduce sitting behavior, and reduce time using the smartphone device.

Author Contributions: Conceptualization, B.S. and A.J.S.-O.; methodology, B.S; formal analysis, A.J.S.-O. and B.S.; investigation, A.J.S.-O. and B.S.; resources, B.S..; data curation, A.J.S.-O.; writing-original draft preparation, C.F and B.S.; writing-review and editing, C.F and B.S; visualization, A.J.S.-O.; supervision, C.F.; funding acquisition, A.J.S.-O. All authors have read and agreed to the published version of the manuscript.

Funding: This research was funded by University of Seville, agreement 4.1/Consejo de Gobierno de la Universidad de Sevilla de 21-12-16, from Teaching Coordination and Innovation (ref. 1.2.3)- 2017/2018.

Conflicts of Interest: The authors declare no conflict of interest.

\section{References}

1. Ammar, A.; Brach, M.; Trabelsi, K.; Chtourou, H.; Boukhris, O.; Masmoudi, L.; Bouaziz, B.; Bentlage, E.; How, D.; Ahmed, M.; et al. Effects of Covid-19 Home Confinement on Physical Activity and Eating Behaviour Preliminary Results of The Eclb-Covid19 International Online-Survey. MedRxiv 2020. Available online: https://www.medrxiv.org/content/10.1101/2020.05.04.20072447v1.full.pdf (accessed on 22 July 2020).

2. Cheval, B.; Sivaramakrishnan, H.; Maltagliati, S.; Fessler, L.; Forestier, C.; Sarrazin, P.; Orsholits, D.; Chalabaev, A.; Sander, D.; Ntoumanis, N.; et al. Relationships Between Changes in Self-Reported Physical Activity and Sedentary Behaviours and Health During the Coronavirus (Covid-19) Pandemic in France And Switzerland. Sportrxiv. Available online: https://osf.io/preprints/sportrxiv/ydv84/ (accessed on 22 July 2020).

3. De Oliveira-Neto, L.; Elsangedy, H.M.; Tavares, V.D.O.; Behm, D.G.; Da Silva-Grigoletto, M.E. \#Traininginhome-Training at Home During The Covid-19 (Sars-Cov2) Pandemic: Physical Exercise And Behavior-Based Approach. Brazilian J. Exerc. Physiol. 2020, 19, 9-19.

4. Sun, S.; Folarin, A.; Ranjan, Y.; Rashid, Z.; Conde, P.; Stewart, C.; Cummins, N.; Matcham, F.; Costa, G.D.; Leocani, L.; et al. Using Smartphones and Wearable Devices to Monitor Behavioural Changes During Covid-19. arXiv 2020, arXiv:2004.14331.

5. Huckins, J.F.; Dasilva, A.W.; Wang, W.; Hedlund, E.L.; Rogers, C.; Nepal, S.K.; Wu, J.; Obuchi, M.; I Murphy, E.; Meyer, M.L.; et al. Mental Health And Behavior During The Early Phases Of The Covid-19 Pandemic: A Longitudinal Mobile Smartphone And Ecological Momentary Assessment Study In College Students. Psyarxiv 2020, 22, e20185.

6. Lippi, G.; Henry, B.M.; Sanchis-Gomar, F. Physical Inactivity and Cardiovascular Disease at the Time of Coronavirus Disease 2019 (Covid-19). Eur. J. Prev. Cardiol. 2020, 27, 204748732091682. [CrossRef]

7. Sallis, J.F.; Adlakha, D.; Oyeyemi, A.; Salvo, D. An International Physical Activity and Public Health Research Agenda to Inform Covid-19 Policies and Practices. J. Sport Health Sci. 2020. Available online: https://www.ncbi.nlm.nih.gov/pmc/articles/PMC7243764/ (accessed on 22 July 2020).

8. Young, D.R.; Hivert, M.-F.; Alhassan, S.; Camhi, S.M.; Ferguson, J.F.; Katzmarzyk, P.T.; Lewis, C.E.; Owen, N.; Perry, C.K.; Siddique, J.; et al. Sedentary Behavior and Cardiovascular Morbidity and Mortality: A Science Advisory from the American Heart Association. Circulation 2016, 134, E262-E279. [CrossRef] [PubMed]

9. Celis-Morales, C.A.; Lyall, D.M.; Steell, L.; Gray, S.R.; Iliodromiti, S.; Anderson, J.; Mackay, D.F.; Welsh, P.; Yates, T.; Pell, J.P.; et al. Associations of Discretionary Screen Time with Mortality, Cardiovascular Disease and Cancer Are Attenuated by Strength, Fitness and Physical Activity: Findings from the UK Biobank Study. BMC Med. 2018, 16, 77. [CrossRef] 
10. Pratt, M.; Ramirez Varela, A.; Salvo, D.; Kohl, H.W., III; Ding, D. Attacking the Pandemic of Physical Inactivity: What Is Holding Us Back? Br. J. Sports Med. 2020, 54. [CrossRef]

11. Saint-Maurice, P.F.; Troiano, R.P.; Bassett, D.R.; Graubard, B.I.; Carlson, S.A.; Shiroma, E.J.; Fulton, J.E.; Matthews, C.E. Association of Daily Step Count and Step Intensity with Mortality Among Us Adults. JAMA 2020, 323, 1151. [CrossRef]

12. Charansonney, O.L. Physical Activity and Aging: A Life-Long Story. Discov. Med. 2011, 12, 177-185.

13. Krogh-Madsen, R.; Thyfault, J.P.; Broholm, C.; Mortensen, O.H.; Olsen, R.H.; Mounier, R.; Plomgaard, P.; Van Hall, G.; Booth, F.W.; Pedersen, B.K. A 2-Wk Reduction of Ambulatory Activity Attenuates Peripheral Insulin Sensitivity. J. Appl. Physiol. 2010, 108, 1034-1040. [CrossRef] [PubMed]

14. Chen, P.; Mao, L.; Nassis, G.P.; Harmer, P.; Ainsworth, B.E.; Li, F. Coronavirus Disease (Covid-19): The Need to Maintain Regular Physical Activity while Taking Precautions. J. Sport Health Sci. 2020, 9, 103-104. [CrossRef] [PubMed]

15. Piercy, K.L.; Troiano, R.P.; Ballard, R.M.; Carlson, S.A.; Fulton, J.E.; Galuska, D.A.; George, S.M.; Olson, R.D. The Physical Activity Guidelines for Americans. JAMA 2018, 320, 2020. [CrossRef]

16. Ricci, F.; Izzicupo, P.; Moscucci, F.; Sciomer, S.; Maffei, S.; Di Baldassarre, A.; Mattioli, A.V.; Gallina, S. Recommendations for Physical Inactivity and Sedentary Behavior During the Coronavirus Disease (Covid-19) Pandemic. Front. Public Health 2020, 8, 199. [CrossRef]

17. Mandolesi, L.; Polverino, A.; Montuori, S.; Foti, F.; Ferraioli, G.; Sorrentino, P.; Sorrentino, G. Effects of Physical Exercise on Cognitive Functioning and Wellbeing: Biological And Psychological Benefits. Front. Psychol. 2018, 9, 509. [CrossRef]

18. De Moor, M.H.M.; Beem, A.L.; Stubbe, J.H.; Boomsma, D.I.; De Geus, E.J.C. Regular Exercise, Anxiety, Depression and Personality: A Population-Based Study. Prev. Med. 2006, 42, 273-279. [CrossRef]

19. Abdulah, D.M.; Musa, D.H. Insomnia and Stress of Physicians During Covid-19 Outbreak. Sleep Med. X 2020, 100017. Available online: https://www.sciencedirect.com/science/article/pii/S2590142720300069?via\%3Dihub (accessed on 22 July 2020). [CrossRef]

20. Zhang, Y.; Zhang, H.; Ma, X.; Di, Q. Mental Health Problems During the Covid-19 Pandemics and the Mitigation Effects of Exercise: A Longitudinal Study of College Students in China. Int. J. Environ. Res. Public Health 2020, 17, 3722. [CrossRef]

21. Hosker, D.K.; Elkins, R.M.; Potter, M.P. Promoting Mental Health and Wellness in Youth Through Physical Activity, Nutrition, and Sleep. Child Adolesc. Psychiatr. Clin. N. Am. 2019, 28, 171-193. [CrossRef]

22. Brauer, A.A.; Athey, A.B.; Ross, M.J.; Grandner, M.A. Sleep and Health Among Collegiate Student Athletes. Chest 2019, 156, 1234-1245. [CrossRef]

23. Zhang, C.; Yang, L.; Liu, S.; Ma, S.; Wang, Y.; Cai, Z.; Du, H.; Li, R.; Kang, L.; Su, M.; et al. Survey of Insomnia and Related Social Psychological Factors among Medical Staff Involved in the 2019 Novel Coronavirus Disease Outbreak. Front. Psychiatry 2020, 11, 306. [CrossRef] [PubMed]

24. Altena, E.; Baglioni, C.; Espie, C.A.; Ellis, J.; Gavriloff, D.; Holzinger, B.; Schlarb, A.; Frase, L.; Jernelöv, S.; Riemann, D. Dealing with Sleep Problems During Home Confinement Due to the Covid-19 Outbreak: Practical Recommendations from A Task Force of the European Cbt-I Academy. J. Sleep Res. 2020, E13052. [CrossRef] [PubMed]

25. Orgilés, M.; Morales, A.; Delvecchio, E.; Mazzeschi, C.; Espada, J.P. Immediate Psychological Effects of the Covid-19 Quarantine in Youth from Italy And Spain. Available online: https://ssrn.com/abstract=3588552 (accessed on 22 July 2020).

26. Sexton-Radek, K.; Burkes, B.; Levitt, T.; Baxter, E.; Dinardi, A. Global Sleep Health in A Covid-19 Virus-Infected World. Int. Med. 2020, 2, 99-101. [CrossRef]

27. Orzech, K.M.; Grandner, M.A.; Roane, B.M.; Carskadon, M.A. Digital Media Use in The 2 H Before Bedtime Is Associated with Sleep Variables in University Students. Comput. Hum. Behav. 2016, 55, 43-50. [CrossRef]

28. Grimaldi-Puyana, M.; Fernández-Batanero, J.M.; Fennell, C.; Sañudo, B. Associations of Objectively-Assessed Smartphone Use with Physical Activity, Sedentary Behavior, Mood, and Sleep Quality in Young Adults: A Cross-Sectional Study. Int. J. Environ. Res. Public Health 2020, 17, 3499. [CrossRef] 
29. Cellini, N.; Canale, N.; Mioni, G.; Costa, S. Changes in Sleep Pattern, Sense of Time and Digital Media Use During Covid-19 Lockdown in Italy. J. Sleep Res. 2020, E13074. [CrossRef]

30. Voitsidis, P.; Gliatas, I.; Bairachtari, V.; Papadopoulou, K.; Papageorgiou, G.; Parlapani, E.; Syngelakis, M.; Holeva, V.; Diakogiannis, I. Insomnia During the Covid-19 Pandemic in A Greek Population. Psychiatry Res. 2020, 289, 113076. [CrossRef]

31. Paradiso, R.; Alonso, A.; Cianflone, D.; Milsis, A.; Vavouras, T.; Malliopoulos, C. Remote Health Monitoring with Wearable Non-Invasive Mobile System: The Healthwear Project. In Proceedings of the 2008 30th Annual International Conference of the IEEE Engineering in Medicine and Biology Society, Vancouver, Bc, Canada, 20-25 August 2008; pp. 1699-1702.

32. Levenson, J.C.; Shensa, A.; Sidani, J.E.; Colditz, J.B.; Primack, B.A. Social Media Use Before Bed and Sleep Disturbance Among Young Adults in The United States: A Nationally Representative Study. Sleep 2017, 40, Zsx113. [CrossRef]

33. Xie, J.; Wen, D.; Liang, L.; Jia, Y.; Gao, L.; Lei, J. Evaluating the Validity of Current Mainstream Wearable Devices in Fitness Tracking Under Various Physical Activities: Comparative Study. JMIR Mhealth Uhealth 2018, 6, E94. [CrossRef]

34. Craig, C.L.; Marshall, A.L.; Sjöström, M.; Bauman, A.E.; Booth, M.L.; Ainsworth, B.E.; Pratt, M.; Ekelund, U.; Yngve, A.; Sallis, J.F.; et al. International Physical Activity Questionnaire: 12-Country Reliability and Validity. Med. Sci. Sports Exerc. 2003, 35, 1381-1395. [CrossRef]

35. Ameen, M.S.; Cheung, L.M.; Hauser, T.; Hahn, M.A.; Schabus, M. About the Accuracy And Problems of Consumer Devices in The Assessment of Sleep. Sensors 2019, 19, 4160. [CrossRef] [PubMed]

36. Royuela Rico, A.; Macías Fernández, J.A. Propiedades Clinimétricas De La Versión Castellana Del Cuestionario De Pittsburgh. Vigilia Sueño 1997, 9, 81-94.

37. Buysse, D.J.; Reynolds, C.F.; Monk, T.H.; Berman, S.R.; Kupfer, D.J. The Pittsburgh Sleep Quality Index: A New Instrument for Psychiatric Practice and Research. Psychiatry Res. 1989, 28, 193-213. [CrossRef]

38. Fakhouri, T.H.I.; Hughes, J.P.; Brody, D.J.; Kit, B.K.; Ogden, C.L. Physical Activity and Screen-Time Viewing Among Elementary School-Aged Children in the United States from 2009 to 2010. JAMA Pediatr. 2013, 167, 223-229. [CrossRef] [PubMed]

39. Tison, G.H.; Avram, R.; Kuhar, P.; Abreau, S.; Marcus, G.M.; Pletcher, M.J.; Olgin, J.E. Worldwide Effect of Covid-19 on Physical Activity: A Descriptive Study. Ann. Intern. Med.. in press.

40. Ekelund, U.; Steene-Johannessen, J.; Brown, W.J.; Fagerland, M.W.; Owen, N.; Powell, K.E.; Bauman, A.; Lee, I.-M. Does Physical Activity Attenuate, or Even Eliminate, The Detrimental Association of Sitting Time with Mortality? A Harmonised Meta-Analysis of Data from More Than 1 Million Men and Women. Lancet 2016, 388, 1302-1310. [CrossRef]

41. Conroy, D.E.; Maher, J.P.; Elavsky, S.; Hyde, A.L.; Doerksen, S.E. Sedentary Behavior as A Daily Process Regulated by Habits and Intentions. Health Psychol. 2013, 32, 1149. [CrossRef]

42. Van Dyck, D.; Cardon, G.; Deforche, B.; Owen, N.; De Cocker, K.; Wijndaele, K.; De Bourdeaudhuij, I. Socio-Demographic, Psychosocial and Home-Environmental Attributes Associated with Adults' Domestic Screen Time. BMC Public Health 2011, 11, 668. [CrossRef]

43. Gamaldo, C.E.; Shaikh, A.K.; Mcarthur, J.C. The Sleep-Immunity Relationship. Neurol. Clin. 2012, 30, 1313-1343. [CrossRef]

44. Potter, G.D.M.; Skene, D.J.; Arendt, J.; Cade, J.E.; Grant, P.J.; Hardie, L.J. Circadian Rhythm and Sleep Disruption: Causes, Metabolic Consequences, and Countermeasures. Endocr. Rev. 2016, 37, 584-608. [CrossRef]

45. Lazzerini, M.; Putoto, G. Covid-19 In Italy: Momentous Decisions and Many Uncertainties. Lancet Glob. Health 2020, 8, E641-E642. [CrossRef]

46. Hall, G.; Laddu, D.R.; Phillips, S.A.; Lavie, C.J.; Arena, R. A Tale of Two Pandemics: How Will Covid-19 And Global Trends in Physical Inactivity and Sedentary Behavior Affect One Another? Prog. Cardiovasc. Dis. 2020. Available online: https://www.ncbi.nlm.nih.gov/pmc/articles/PMC7194897/ (accessed on 22 July 2020). [CrossRef] [PubMed]

47. De Souza Filho, B.A.B.; Tritany, É.F. Covid-19: Importância Das Novas Tecnologias Para A Prática De Atividades Físicas Como Estratégia De Saúde Pública. Cad. Saude Publica 2020, 36, E00054420. [CrossRef] [PubMed] 
48. De Matias, G.H.L.; Guerra, A.C.C.G.; De Souza Filho, B.A.B.; De Lima, J.T.O.; Do Carmo, C.N.; Mattos, I.E. Repetibilidade E Reprodutibilidade De Um Manual De Exercícios Físicos Domiciliares. Fisioter. E Pesqui. 2018, 25, 209-216. [CrossRef]

49. Stamatakis, E.; Ekelund, U.; Ding, D.; Hamer, M.; Bauman, A.E.; Lee, I.M. Is The Time Right for Quantitative Public Health Guidelines on Sitting? A Narrative Review of Sedentary Behaviour Research Paradigms and Findings. Br. J. Sports Med. 2018, 53, 377-382. [CrossRef] 